were made by the Governor-General and the Commander-inChief to procure doctors as after the battle of Waterloo, and with a similar result. They came too late.

"I have in my possession a report from a medical officer of the Company's service on the state of the wounded three months after the first battle, which it would answer no good purpose to publish. It would be what might have been said of the state of the wounded in Portugal and Spain during the first four years of that war. The official statistical returns of the sick and wounded during the first Burmese war, show a loss of $45 \frac{1}{2}$ per cent; ; those, if published, of the war in China will, I understand, be no better. The cause is well knownthe remedy is in great part attainable. The evil remains.

"When Charles VI. of France sent to Spain, in aid of Pedro the Cruel, the renowned warrior Bertrand Du Guesclin, at the head of the reiters, the lansquenets, the free compaynons of his army, from whose prowess he had derived the greatest advantrges, and heard in due time that their bones were whitening the fields of Castille and Navarre, he drew consolation from the fact that they could not return, and would not be able to claim the rewards, the pensions he had promised, and to which their services entitled them. After the lapse of three centuries, no better consolation can be afforded to the people of Great Britain under a similar but more severe infliction.

"The royal army of Great Britain is not composed of mercenaries. Its soldiers are the blood, the bone, the sinew of the nation, on whose indomitable valour alone can dependence be placed in the hour of danger. By them the victory must be won; by them the loss must be sustained; and a country grateful for their services should watch over them in their necessities as a mother over her children."

My private efforts having thus failed on two important points, it may not perhaps be considered improperly importunate to endeavour now to ascertain what may be the public feeling on the subject of the care which ought to be bestowed on the wounded soldier. If it should appear that the public are indifferent, I will willingly submit to be considered a troublesome person, whose philanthropy has got the better of his judgment. If, on the contrary, the public declare that the treatment of the wounded soldier on the field of battle and afterwards should be as effective as possible, I will endeavour to show what ought to be done to accomplish the object. Of the favourable intentions of the great authorities of the country - of the Commander in Chief in particular-I have never doubted. It is from the small, secondary authorities in the different offices of the four or five departments each measure proposed has to go through that discomfiture has hitherto occurred, and will probably again take place.

\section{ON MILITARY MEDICAL EDUCATION.}

By SIr GEORGE BALLINGALL,

PROFESSOR OF MILITARY SURGERY IN THE UNIVERSTTY ON EDINBURGH.

To the Eatitor of THE LANCET.

SrR, - It is with no common interest that I have read the letter of my friend Mr. Guthrie, "On the Medical Service of the British Army." The substance of that letter it was my privilege to peruse, in Mr. Guthrie's room, several years ago, but no persuasion could induce him, at that time, (for the reasons he has stated,) to give me a copy of it, or to permit me to read it to my pupils. It would be idle and impertinent in me to attempt to add anything to what has been so forcibly urged from the unexampled experience of my friend, but there is one point connected with this subject on which I may possibly be permitted to offer an opinion.

I have now held the Professorship of Military Surgery in the University of Edinburgh for nearly two-and-thirty years, during which period several hundreds of old army and navy surgeons have attended my lectures, and many hundreds of young men have had their attention turned to those measures tending to diminish the mortality incident to protracted campaigns. "We have lately," says the editor of The Times, "been introduced to some elaborate calculations, purporting to show that preventible diseases carry off ten times the number of victims laid low in the most sanguinary engagements." "The actual bulletins of a campaign will undoubtedly give very striking results as to the smallness of the numbers slain in battle, but these numbers must be multiplied at least by ten to show the true consumption of life in war."

In a letter addressed, some ten years ago, to the late Sir
Robert Peel, the patron of my chair at the time $I$ was appointed to it, and in a series of introductory lectures, I have urged the establishment in the other metropolitan cities, London and Dublin, of lectureships similar to the one I hold. In this I have been ably seconded by a succession of leading articles in THE LANCET, and other professional journals, and I appeal with confidence to the opinion of my old pupils in confirmation of the views I entertain as to what may be done by the united efforts of men devoted to the collection and diffusion of the accumulated and accumulating experience of the army and navy surgeons.

But let not this matter rest upon medical testimony alone, I appeal to the opinion of numerous general and field officers, from whom $I$ have been honoured with communications, and who, while ready to acknowledge the professional services of their medical officers generally, lament their want of information on many points of military hygiene. Amongst these I would first mention the name of Sir De Lacy Evans, who brought this subject forward in an energetic appeal to the House of Commons, during the last session of Parliament. I hope I may also be permitted to mention the names of the Earl of Cathcart, Sir Thomas Brisbane, Sir Neil Douglas, and my old brother officer General Wetherall. Two of these distinguished officers long held the chief command of the troops in Scotland, another has for many years been the president of the Royal Society of Edinburgh, and all have had the best opportunities of knowing what is done here. But I have never rested this important question upon what has been done, but upon what has been best.

Notwithstanding the energetic, the untiring, the admirable exertions of your correspondent Mr. Guthrie, and others, there still lies open a vast field of bygone experience which I hold to be yet but imperfectly cultivated; and I trust that we are not going to enter upon another and a novel field of professional improvement without being in every way prepared to turn it to the utmost advantage. Old as I am, closely approaching to the three-score and ten, if I am destined to witness the commencement of another European conflict, I shall not be slow to watch the progress of events, to receire, I trust, as I have hitherto done, numerous communications from my old pupils, similar to those quoted in Mr. Guthrie's letter, and to do my best to press upon the attention of my auditors the many circumstances, whether prosperons or adverse, which so materially influence the health, vigour, and efficiency of the soldier and seaman, whether as regards the prevention of disease, the succour to be given to the wounded, or the comfort which may be afforded them in the wearisome hours which they must pass in the hospital. My utmost ambition is that in each of the other metropolitan schools of physic a colleague should be associated with me in the discharge of duties, which I know to be interesting to the rising generation of army and navy surgeons, and which may be made most conducive to the best interests of her Majesty's service.

I am, Sir, your very obedient servant,

Edinburgl, Feb. 1854 George Ballingall.

\section{SUGGESTIONS REGARDING THE APPOINT-} MEN'T OF INSPECTORS OF HEAITH IN THE ARMY.

BY THE IATE DR. ROBERT JACKSON, THE GREAT MILITARY SURGEON.

(Communicated by J. RAYALD MARTIN, F.R.S., and never before published.)

THe appointment of a person of the medical profession, for the inspection and arrangement of the matters which relate to health in barracks, camps, and transport-ships, bears on the face of it an obvious purpose of utility; but whether it prove useful or not on trial, will depend upon the zeal and ability with which the duty is executed. The causes which affect human health are often obscure, many of them so subtile that they are discerned with difficulty, and can only be appreciated by those who devote their time to the study and observation of them through all their changes. They even sometimes escape the keenest observation of the most accurate observers ; yet it is reasonable to suppose that those who prosecute such investigations with zeal actually make some progress in knowledge; and if any discovery of knowledge be made, it is not a matter of doubt that it should be employed to assure the public good. It is easier to preserve health than to cure disease, and it implies less expense of means. If any information on the subject of preserving health in barracks, camps, or embarka- 
tions, clear in principle, and administrative of direct utility in practice, be submitted to the consideration of the chiefs in these departments, by a medical officer attached to their department, it will not fail to be acted upon, and, being acted upon, it will produce a positive good, or avert an impending evil. The office suggested, important if well executed, implies a great deal of personal labour; for everything must be personally and accurately inspected before the real truth of things can be known: the real cause is frequently not the obvious cause. The office suggested relates only to the means of preserving the health of the soldiers; the cure of disease, and the arrangements adopted. for that purpose, belong to another department.

\section{ON}

\section{SCIATICA AND ITS TREATMENT WITH CROTON OIL.}

BY HENRY HANCOCK, Esq., F.R.C.S., SURGEON TO CHARIYG-CROSS HOSPITAL.

VARIOUS causes have been assigned as producing sciatica,viz., disorder of the stomach and bowels; inflammation and disease of the sciatic nerve; syphilis; gout; obstruction and distension of the caput coli; tumours or accumulated fres in the course of the nerve; effusion of fluid into the sheath of the nerve; irritation and disordered state of the kidneys; and rheumatism, either acute or subacute.

The most ancient writer upon the subject of sciatica was Cotunnius, physician to the Emperor of Austria, who published a treatise at Vienna in the year 1770 , entitled, "De Ischiade," and of which an English translation appeared in 1775. His idea was that sciatica depended upon the effusion of fluid into the sheath; but, if I may judge from the cases which have fallen under my own observation, the prevailing opinion is, that sciatica depends mostly upon rheumatism or inflammation of the nerve-an opinion which appears to me to be erroneous, inssmuch as having been frequently consulted in cases of sciatica which had previously been treated according to this notion, and having likewise had ample opportunities of forming an opinion, I am convinced that the cause most productive of this complaint is irritation of the nerve within the pelvis, either from loaded colon or cæcum, or from tumonrs formed within that cavity, and acting mechanically upon the nerve in that situation. And I would here venture to suggest the propriety of bearing this in mind, as I firmly believe that were cases of sciatica treated generally according to these views, it would be found that the exception would form but a very small minority indeed.

When the causes are so various, we cannot feel surprised that the treatment proposed should be varied also. And accordingly we find Cotunnius advised cupping, leeches, followed by issues and blisters; Dr. Wilson advises bleeding, blistering, calomel and opium, colchicum, turpentine, and carbonate of iron; Dr. Christison gives Indian hemp; Dr. Bery, of Viberg, the bisulphuret of carbon, both internally and externally; Dr. Kirby, of Dublin, the tincture of aconite with colchicum, with Battley's solution of opium at night. In Ranking's Abstract for 1853 , p. 37, we find the account of a case treated by M. Robert by the application of the actual cautery along the dorsal aspect of the foot, in a line drawn from the external malleolus to the third and fourth toes. Dr. Be?combe, of York, gives acetate of potash with infusion of senna, and advocates the employment of acupuncture; Mr. Ryud, of the Meath Hospital, Dublin; punctures the $\operatorname{limb}$ in the course of the nerve, and introduces ten grains of morphia with one drachm of creasote; whilst Dr. Graves recommends opinm in large doses. . The following cases may prove interesting:-

CASE l. -Mrs. W- the wife of a clergyman residing in Essex, consulted me six years ago for sciatica in the right leg, of nearly two years' duration. Her sufferings were most intense, and she was worn almost to a skeleton by their duration and want of rest. She attributed the attack to cold caught by getting wet through, and had during the previous two years been treated accordingly by colchicum and calomel and opium internally, whilst locally she had been cupped, blistered, and counter-irritated by various applications, such as veratria, tartarized antimony, iodine and hydriodate of potash, and croton oil, but without deriving any benefit. For the last six months she had taken morphia to such an extent that she only found relief by doses of three grains each, taken at repeated. intervals when the paroxysms of pain were urgent. Her tongue was much loaded, her breath offensive, and appetite bad; but she assured me she did not require purgative medicine, adding that she could not bear eren the mildest form, she was so extremely delicate, and it acted so violently. Upon carefully examining the large intestines, the crecum and ascending colon appeared distended, and yielded a dull sound on percussion. Under these circumstances, I concluded this was a case depending upon local irritation within the pelvis, and not upon rheumatisin or inflammation of the nerve, and therefore ordered-.-croton oil, one minim; blue pill; extract of hyosciamus, each four grains; compound extract of colocynth, eight grains; to be divided into four pills, two to be taken that night: that she should gradually diminish the quantity of morphia until she left it off entirely, and abstain from solid food until I again saw her, which I did on the day but one after. I then found her much relieved, but extremely angry at the violence of the medicine, which had acted very efficiently, dislodging a large quantity of hard, lumpy, dark. coloured feculent matter. The pain, though diminished, was still very great, but she described it as having assumed the sensation of a severe bruise rather than the intense sharp burning pain which she had hitherto experienced. Her bowels had not acted for twenty-four hours, and as up to the time of their ceasing to act the evacuations were not simply fluid, but continued to present scybalous matter, I prevailed upon her to repeat the pills at night, assuring her that when they ceased to meet with obstruction, they would act less powerfully.

After another interval of a day, I again saw her. She was then (and she expressed herself) much better. The acute pain had entirely left her, and the sensation of bruising was so much diminished that she described it as more like numbness than anything else. She assured me she had not been so well for months. Her tongue was cleaner, abdomen softer, she could now walk across the room without pain, and bad only taken her morphia once on the preceding day; her pulse was weak and her skin cold and clammy. I ordered three grains of the sulphate of quinine every four hours, and the morphia to be discontinued entirely. Under this medicine she rapidly recovered; the sensation of numbness disappeared, and she returned. home cured after being in London for a fortnight.

CASE 2.-Mrs. G_-, residing at Brook-green, consulted me for lumbago and sciatica of the right leg. She had suffered for three months, and had been told it depended upon rheumatism, and was treated accordingly by cupping, blisters, warm bath, colchicum, \&c., but without experiencing any relief. I prescribed the croton-oil pills as in the preceding case. She took them twice, and was cured.

CASE 3.-The Rev. E. C- consulted me for sciatica of the right leg, of two months' duration, but very severe. He is a very talented, strong-minded man, and fond of athletic exercises; but he describes the pain as so intensely severe as to be almost beyond the power of endurance, and that it entirely deprived him of rest, the only easy position being that of sitting; that when he endeavoured to stand upright or to straighten his leg, he could scarcely refrain from calling out. He was first attacked with lumbago after riding in an open gig; but being engaged to shoot the following morning, he applied a large mustard poultice over the loins, which relieved him so much that he thought himself sufficiently recovered to keep his appointment; but after walking for about an hour, his sufferings became so great, he was obliged to return home, and go to bed. He placed himself under the care of a gentleman, who gave him steel and quinine, and citrate of iron with quinine, and also applied chloroform blisters from the hip to the external malleolus by means of strips of lint dipped in the chloroform, and retained by bandage over the course of the nerve. This produced a broad stripe of blistered surface down the entire length of his leg, but increased rather than diminished his sưferings, He sought other advice, but with so little benefit, that he wound up his narration by saying"Mr. Hancock, it is a most remarkable thing, but you gentlemen do not appear to me to understand anything at all about the complaint." His tongue did not indicate anything particular, neither did his pulse. He was fresh-coloured, stout, and full bellied. I told him that, however well the treatment pursued might be adapted to some forms of sciatica, I did not consider they were suited to that under which he was labouring; that I believed nineteen out of every twenty cases of sciatica depended upon mechanical irritation of the nerve within the pelvis by the pressure of the loaded intestine upon it before it left that cavity; and that " had rery little doubt 